\title{
Characteristic Scales for Turbulent Exchange Processes in a Real Urban Canopy
}

\author{
Francesco Barbano $^{1}$ (D) - Erika Brattich ${ }^{1}$. Silvana Di Sabatino ${ }^{1}$ \\ Received: 15 August 2019 / Accepted: 21 July 2020 / Published online: 8 August 2020 \\ (c) The Author(s) 2020
}

\begin{abstract}
An experimental field campaign is designed to unveil mechanisms responsible for turbulent exchange processes when mechanical and thermal effects are entwined. The focus is an urban street canyon with a mean aspect ratio $H / W$ of 1.65 in the business centre of a mid-size Italian city ( $H$ is the mean building height and $W$ is the mean canyon width). The exchange processes can be characterized by time scales and time-scale ratios specific to either mechanical or thermal process. Time scales describe the mixing caused by momentum and heat exchange within different canyon layers, while their rates are surrogates of their efficacy. Given that homogeneous mixing does not always occur within the canyon, several time scales are estimated at different levels, showing that mechanical and thermal processes may both contribute to enhance mixing. By computing mechanical time scales, it is found that the fastest mixing occurs at the canyon rooftop level for perpendicular or oblique wind directions, while slow mixing occurs for parallel directions. Thermal processes are faster than the mechanical ones and are particularly efficient for perpendicular wind directions. By calculating the time-scale ratios, exchange processes are found to facilitate mixing for most wind directions and to regulate the pollutant-concentration variability in the canyon. This variability can be associated with the local-circulation regime, demarcated as thermally driven or inertially driven using a buoyancy parameter, i.e., the ratio between thermal and inertial forcings. Using this approach, a generalization of the results is proposed, enabling the extension of the current investigation to different street-canyon aspect ratios.
\end{abstract}

Keywords City breathability · Exchange processes · Turbulent scales · Urban canopy

\section{Introduction}

Exchange processes between the urban canopy layer and an idealized inertial layer above have been addressed previously (e.g., Barlow and Belcher 2002; Bentham and Britter 2003; Harman et al. 2004) using data from laboratory, field, and numerical experiments. In urban canopies characterized by the skimming-flow regime (Oke 1987), local atmospheric circulation (Britter and Hanna 2003) and exchange processes are driven by turbulence. For an

Francesco Barbano

francesco.barbano3@unibo.it

1 Physics and Astronomy Department, University of Bologna, Via Irnerio 46, Bologna, Italy 
inertially driven circulation (Britter and Hanna 2003), exchange processes are known to be driven by, and scale with, the vertical flux of momentum in the shear layer (Louka et al. 1998; Barlow et al. 2004; Solazzo and Britter 2007; Klein and Galvez 2015), the region of strong velocity gradients induced by the drag resistance of the buildings to the background flow. The efficacy of the exchange processes increases with the intensity of the background flow in the inertial layer (Barlow and Belcher 2002; Harman et al. 2004), the turbulent momentum transport (Kim and Baik 2003), and the turbulence kinetic energy transport (Salizzoni et al. 2011) from the shear layer to the street canyon. The efficacy also varies according to local morphological characteristics (Leo et al. 2018), such as the street-canyon aspect ratio (Barlow and Belcher 2002) and the roof geometry (Kastner-Klein et al. 2004). For an in-canopy thermally-driven circulation, i.e. when the differential heating between opposite building facades is larger than the unperturbed inertial flow (Dallman et al. 2014), exchange processes are modified by the turbulent heat transport (Nazarian et al. 2018), and their efficacy scales with the level of mixing within the canyon and the thermal stratification above (Nazarian et al. 2017). This efficacy is also modified by the heat release from the ground ( $\mathrm{Li}$ et al. 2012).

In addition to studies of a more fundamental nature, such as those cited above, the topic of exchange processes has been addressed to respond to air-quality and urban-meteorology applications. For example, exchange processes have been identified as key mechanisms of pollutant removal from the canyon cavity to the rooftop level. Recently, the terminology used to describe mechanisms of ventilation and pollutant removal is city breathability (Buccolieri et al. 2010; Panagiotou et al. 2013; Chen et al. 2017), which incorporates any scalar (e.g., heat, moisture, pollutant concentration) ejection from ground level, transport throughout a canopy interface, or turnover time scales. The city-breathability concept has been applied to different spatial scales of the urban environment, ranging from street-canyon (Cheng et al. 2009a; Liu and Wong 2014; Di Bernardino et al. 2018), to neighbourhood (Di Sabatino et al. 2007; Soulhac and Salizzoni 2010; Buccolieri et al. 2015), to city (Hang et al. 2012) scales. Despite several field experiments conducted in the last two decades (Louka et al. 2000; Rotach et al. 2005; Eliasson et al. 2006; Kanda and Moriwaki 2006; Nelson et al. 2011; Zajic et al. 2011; Dallman et al. 2013), city breathability has been poorly investigated in real environments owing to the complexity of such investigations.

Following Lo and Ngan (2017), city breathability is assessed by two categories of diagnostic quantities. The first is based on the evaluation of turbulent mass exchange between the canopy and the overlying atmosphere, typically quantified by exchange velocities (Bentham and Britter 2003) or exchange rates (Liu et al. 2005). The second category is based on the evaluation of diagnostic time scales associated with pollutant removal or in-canyon circulation. Within this last category, different time scales have been derived from computational-fluiddynamics simulations and wind-tunnel experiments to characterize the city breathability according to wind direction (Hang et al. 2013), canyon aspect ratio (Liu et al. 2005; Bady et al. 2008; Kato and Huang 2009; Hang et al. 2009; Salizzoni et al. 2009), domain size and morphology (Hang et al. 2012; Buccolieri et al. 2015), pollutant emissions, and turbulence regimes (Lo and Ngan 2017). These time scales are calculated directly using pollutant concentration and emission, and mass transport through the canyon interface. Our main focus is to define new time scales and rates that are independent of the pollutant removal and concentration, and strictly related to the fundamental nature of the exchange processes. These quantities enable the quantification of the speed and efficiency of the process of transferring momentum and heat between the canopy and the atmosphere above, according to the dominant in-canyon circulation and the background wind direction. Moreover, this research intends to clarify whether mass exchange is driven by either mechanical or thermal processes and which of these two is dominant. 
Below, Sect. 2 defines the methodology, and Sect. 3 describes the experimental field campaign and data used to evaluate the method. Section 4 describes the pre-processing of the experimental data, Sect. 5 is devoted to the discussion of the results, and Sect. 6 draws the conclusions.

\section{Methodology}

To quantify the efficacy of mixing in a street canyon related to mechanical and thermal processes, new diagnostic quantities (namely time scales and exchange rates) are derived. Time scales define the time required to generate mixing within different canyon layers caused by momentum and heat exchange. Given that mixing may not be homogeneous and evenly distributed within the canyon, and at its interface with the atmosphere above, four different time scales are defined, distinguishing between mechanical and thermal processes, and rooftop and in-canyon locations. Exchange rates are then evaluated as time-scale ratios to estimate the momentum and heat-exchange factors between the canopy and the atmosphere above.

The derivation of the time scales is performed through the Buckingham theorem (Durst 2008), where the dependent variables describe the fundamental nature of the exchange processes. ${ }^{1}$ The time scales at the rooftop level define the required time to exchange momentum and heat through the interface between the canopy and the atmosphere above. At this level, exchange processes are driven by the local transport of momentum (Louka et al. 1998; Barlow et al. 2004; Solazzo and Britter 2007; Klein and Galvez 2015) and heat (Li et al. 2012; Nazarian et al. 2018) through the interface, and are quantified by the turbulent kinematic momentum $\left.\overline{w^{\prime} u^{\prime}}\right|_{H}$, and heat $\left.\overline{w^{\prime} \theta^{\prime}}\right|_{H}$ fluxes at the rooftop level. Above the canopy, the background flow and thermal stratification can enhance or inhibit the exchange-process efficacy, because the vertical gradients of the mean background wind speed $\Delta U_{b} / \Delta z$ and potential temperature $\Delta \theta_{b} / \Delta z$ favour or prevent vertical mixing (Nazarian et al. 2017). Within the canopy, exchange processes are constrained by the local geometry (Barlow and Belcher 2002; Kastner-Klein et al. 2004), which confines the flow and turbulent structure within a finite volume given by the mean building height $H$, the mean canyon width $W$, and the canyon length $L$. Therefore, at the rooftop level, the mechanical $\tau_{d}^{H}$ and thermal $\tau_{h}^{H}$ time scales are functions $f$ of the following variables,

$$
\begin{aligned}
& \tau_{d}^{H}=f\left(\left.\overline{w^{\prime} u^{\prime}}\right|_{H}, H, W, L, \frac{\Delta U_{b}}{\Delta z}\right), \\
& \tau_{h}^{H}=f\left(\left.\overline{w^{\prime} \theta^{\prime}}\right|_{H}, H, W, L, \frac{\Delta \theta_{b}}{\Delta z}\right) .
\end{aligned}
$$

It is worth mentioning that the choice of both fluxes and gradients can be sustained by the different spatial scales they represent (local for the fluxes, city for the gradients) and by the limited validity of the flux-gradient relationship at the urban-canopy interface. Making use of the Buckingham theorem in Eq. 1, the time scales become

$$
\begin{aligned}
\tau_{d}^{H} & =\frac{H^{3}}{\left.\overline{w^{\prime} u^{\prime}}\right|_{H} W} \frac{\Delta U_{b}}{\Delta z}, \\
\tau_{h}^{H} & =\frac{H^{3}}{\left.\overline{w^{\prime} \theta^{\prime}}\right|_{H} W} \frac{\Delta \theta_{b}}{\Delta z} .
\end{aligned}
$$

\footnotetext{
1 An example application of the Buckingham theorem is presented in Appendix 1.
} 
Time scales increase as the canyon height and the thermal stratification increase, and decrease as the canyon width and the fluxes increase. Equation 2 does not depend on the canyon length $L$ since time scales are only based on vertical transport and vertical flow variation. Moreover, when $L \gg H$ (as in the current domain, see Sect. 3), the exchange processes are supposedly confined to the bi-dimensional plane defined by the vertical and cross-canyon directions and delimited by the geometric parameters $H$ and $W$ of the canyon, repeating themselves along the canyon axis. As a consequence, exchange processes are not supposed to be an extensive variable of the canyon length.

Time scales inside the canyon describe the required time to mix fresh air from the rooftop interface with the stagnant air of the canopy. These time scales depend on the turbulent transport provided by the in-canyon momentum $\left.\overline{w^{\prime} u^{\prime}}\right|_{S}$ and heat $\left.\overline{w^{\prime} \theta^{\prime}}\right|_{S}$ fluxes, which are constrained by the canyon geometry. Fresh air is driven into the canyon through the shear layer, the intensity of which is parametrized by the friction velocity and temperature scale, $u_{*}^{H}=\left.\left(\left.\overline{w^{\prime} u^{\prime}}\right|_{H} ^{2}+\left.\overline{w^{\prime} v^{\prime}}\right|_{H} ^{2}\right)^{1 / 4} \approx \overline{w^{\prime} u^{\prime}}\right|_{H} ^{1 / 2}$ and $\theta_{*}^{H}=\left.\overline{w^{\prime} \theta^{\prime}}\right|_{H} / u_{*}^{H}$ respectively. Therefore, within the canopy, the time scales are functions of the following variables,

$$
\begin{aligned}
\tau_{d}^{S} & =f\left(\left.\overline{w^{\prime} u^{\prime}}\right|_{S}, W, L, H, u_{*}^{H}\right), \\
\tau_{h}^{S} & =f\left(\left.\overline{w^{\prime} \theta^{\prime}}\right|_{S}, W, L, H, u_{*}^{H}, \theta_{*}^{H}\right),
\end{aligned}
$$

where the friction velocity $u_{*}^{H}$, and the temperature scale $\theta_{*}^{H}$ are constant values computed at the rooftop level for each wind direction. Using again the Buckingham theorem on Eq. 3, the in-canyon time scales become

$$
\begin{aligned}
\tau_{d}^{S} & =\frac{H^{2} u_{*}^{H}}{\left.\overline{w^{\prime} u^{\prime}}\right|_{S} W}, \\
\tau_{h}^{S} & =\frac{H^{2} \theta_{*}^{H}}{\left.\overline{w^{\prime} \theta^{\prime}}\right|_{S} W} .
\end{aligned}
$$

The in-canyon time scales increase when the shear-layer friction and the canyon height increase. Conversely, time scales decrease as the vertical transport and the canyon width increase. Like the rooftop-level evaluation, the time scales within the canyon are again independent of the canyon length $L$. The thermal time scale $\tau_{h}^{S}$ in Eq. $4 \mathrm{~b}$ does not depend explicitly on the friction velocity $u_{*}^{H}$ because the friction-velocity contribution is provided by the temperature scale $\theta_{*}^{H}$.

The exchange rates (i.e. the ratios between the time scales within and above the canyon) describe the relative mixing time caused by momentum and heat exchange between different atmospheric layers. Thus, exchange rates provide information about the transport efficacy from the canopy to the atmosphere above, and can be defined as

$$
\begin{aligned}
& \eta_{d}=\frac{\tau_{d}^{S}}{\tau_{d}^{H}}=\frac{\left.\overline{w^{\prime} u^{\prime}}\right|_{H}}{\left.\overline{w^{\prime} u^{\prime}}\right|_{S}} \frac{u_{*}^{H}}{H} \frac{\Delta z}{\Delta U_{b}}, \\
& \eta_{h}=\frac{\tau_{h}^{S}}{\tau_{h}^{H}}=\frac{\left.\overline{w^{\prime} \theta^{\prime}}\right|_{H}}{\left.\overline{w^{\prime} \theta^{\prime}}\right|_{S}} \frac{\theta_{*}^{H}}{H} \frac{\Delta z}{\Delta \theta_{b}} .
\end{aligned}
$$

The ratio of kinematic fluxes in Eq. 5 drive the relative transport of momentum and heat between the canopy and the rooftop interface. Friction parameters, background-flow gradients, and the canyon height modulate the magnitude of this ratio, modifying the efficacy of the rates. An explicit dependence on the canyon width $W$ is lost in the ratios, but $W$ is still accounted for in the definition of the time scales. As long as $\tau^{H}>\tau^{S}$, air within the 




Fig. 1 Measurement sites (a) and frontal view from north (b) of Marconi Street. Colours link the locations (dots) to the corresponding measurement levels (boxes). Table 1 lists the instrumentation deployed at each level. . (Source: https://www.openstreetmap.org)

canyon is efficiently mixed with fresh air from above, which suggests that the entire canyon is well mixed, allowing momentum and heat to be efficiently transported out of the canyon. Conversely, when $\tau^{H}<\tau^{S}$, mixing inside the canyon is slower than mixing at the rooftop, in which case the vertical momentum and heat transport are expected to be suppressed. Since Eq. 5 provides information about the refreshing properties of the canyon, these relationships can be used to interpret pollutant-concentration variation within the canyon.

Although time scales and rates do not account for the wind direction explicitly, it is likely that application of the method to a real environment requires a dicretization per wind direction.

\section{Field Campaign Description}

The quantities described in Sect. 2 are evaluated using field measurements collected during an extensive field campaign from 7 August to 26 September 2017 within the city centre of Bologna $\left(44^{\circ} 29^{\prime} \mathrm{N}, 11^{\circ} 20^{\prime} \mathrm{E}, 56 \mathrm{~m}\right.$ above mean sea level), a medium-size city located in northern Italy. Bologna is located in the southern part of the Po Valley, bounded to the south by the Apennines chain. Due to its geographical location and the low wind speeds characterizing the Po Valley (Mazzola et al. 2010), Bologna is a well-recognized hotspot of air pollution in Europe (Finardi et al. 2014). The morphology of Bologna is considered typical for European cities (Ratti et al. 2002; Di Sabatino et al. 2010), characterized by a historical, densely-built centre surrounded by residential and industrial areas. The neighbourhood scale is a dense network of street canyons only interrupted by occasional squares or junctions. Therefore, a street canyon (Marconi Street shown in Fig. 1b) was selected as the field domain for the campaign.

It is a long (canyon length $L \approx 600 \mathrm{~m}$ ) main bus artery located in the core of the business centre (Fig. 2 b). The street is composed of four lanes (mean canyon width $W \approx 20 \mathrm{~m}$ ) bounded by tall and densely-packed buildings (mean canyon height $H \approx 33 \mathrm{~m}$ a.g.1.), interrupted by a few small junctions and one major intersection. Despite traffic being restricted to only residents and certain citizens, the traffic in Marconi Street is intense as more than the 50\% of Bologna bus lines enter this street. 




Fig. 2 Campaign measurement sites. From left to right: Silvani Street (a), Marconi Street (b), and Asinelli Tower (c). . (Source: https://www.openstreetmap.org)

The street is displaced $17^{\circ}$ to the east from the north- south direction and it is almost free of vegetation. Therefore, wind directions of $087^{\circ}-127^{\circ}$ or $267^{\circ}-307^{\circ}$ are considered as perpendicular to the canyon, while $357^{\circ}-037^{\circ}$ and $177^{\circ}-217^{\circ}$ are parallel from the north and from the south, respectively. In addition, flow coming from the south-west (sector $222^{\circ}-262^{\circ}$ ) is also investigated.

The experimental campaign was originally designed to study turbulence and local-scale dynamics and thermodynamics within a real urban environment, and to characterize local air quality. To fulfil these goals, three levels within (2) and above (1) Marconi Street, (namely rooftop, mid-canyon and ground levels, Fig. 1a), were fully equipped and supported by external meteorological stations (Fig. 2). lists the instrumentation deployed in the field. All three sites in Marconi Street were equipped with sonic anemometers and thermohygrometers suitable for the evaluation of turbulence. Air-pollution concentrations were measured at the ground-level site, i.e. in the proximity of the traffic-related emission source, with an ad hoc instrumented van of the Emilia-Romagna Environmental Protection Agency (ARPAE). Background-flow characteristics (variables with subscript $b$ in Sect. 2) were retrieved from two meteorological stations from the ARPAE permanent network located at the top of the tallest building in Silvani Street (Fig. 2a) and at the top of the Asinelli Tower in the city centre (Fig. 2c). Appendix 2 details the instrumentation used for the experimental campaign.

For the purposes of our study, a suitable dataset of four days (20-23 September 2017) was selected to support the choice of weak synoptic conditions, when local circulation is supposed to dominate the small-scale dynamics. 
Table 1 Instrumentation set-up, sample rate, relevant measurements and uses of the collected data

\begin{tabular}{|c|c|c|c|c|}
\hline Level & Instrumentation & Sample rate & Measurements & Derived quantities \\
\hline $\begin{array}{l}\text { Rooftop } \\
\text { (33 m a.g.1.) }\end{array}$ & $\begin{array}{l}\text { Sonic anemometer } \\
\text { uSonic-3 }\end{array}$ & $10 \mathrm{~Hz}$ & $\begin{array}{l}\text { Velocity } \\
\text { Sonic temperature }\end{array}$ & $\begin{array}{l}U_{H}, W D, T \\
\left.\overline{w^{\prime} u^{\prime}}\right|_{H},\left.\overline{w^{\prime} \theta^{\prime}}\right|_{H} \\
u_{*}^{H}, \theta_{*}^{H} \\
\tau_{d}, \tau_{h}, \\
\eta_{d}, \eta_{h}, \eta_{t}, \\
C_{0}\end{array}$ \\
\hline \multirow[t]{2}{*}{$\begin{array}{l}\text { Mid-canyon } \\
\text { ( } 7 \text { m a.g.1.) }\end{array}$} & $\begin{array}{l}\text { Sonic anemometer } \\
\text { Windmaster 3D, }\end{array}$ & $20 \mathrm{~Hz}$ & $\begin{array}{l}\text { Velocity, } \\
\text { Sonic temperature }\end{array}$ & $\begin{array}{l}\left.\overline{w^{\prime} u^{\prime}}\right|_{S},\left.\overline{w^{\prime} \theta^{\prime}}\right|_{S} \\
\tau_{d}, \tau_{h} \\
\eta_{d}, \eta_{h}, \eta_{t} \\
U_{m a}, U_{m a}^{m}\end{array}$ \\
\hline & $\begin{array}{l}\text { Thermohygrometer } \\
\text { HCS2S3-L }\end{array}$ & $1 \mathrm{~Hz}$ & Air temperature & $\begin{array}{l}T_{2, m}, \alpha \\
B, \Delta T\end{array}$ \\
\hline \multirow[t]{3}{*}{$\begin{array}{l}\text { Ground } \\
\text { (4 m a.g.1.) }\end{array}$} & $\begin{array}{l}\text { Sonic anemometer } \\
\text { Windmaster 3D, }\end{array}$ & $20 \mathrm{~Hz}$ & $\begin{array}{l}\text { Velocity, } \\
\text { Sonic temperature }\end{array}$ & $\begin{array}{l}\left.\overline{w^{\prime} u^{\prime}}\right|_{S},\left.\overline{w^{\prime} \theta^{\prime}}\right|_{S} \\
\tau_{d}, \tau_{h} \\
\eta_{d}, \eta_{h}, \eta_{t} \\
U_{m a}, U_{m a}^{m}\end{array}$ \\
\hline & $\begin{array}{l}\text { Thermohygrometer } \\
\text { HCS2S3-L, }\end{array}$ & $1 \mathrm{~Hz}$ & Air temperature & $\begin{array}{l}T_{1, m}, \alpha \\
B, \Delta T, \Delta T^{m}\end{array}$ \\
\hline & $\begin{array}{l}\text { Gas analyzer } \\
\text { T300 }\end{array}$ & $\begin{array}{l}1 \mathrm{~min} \\
\text { (average) }\end{array}$ & $\begin{array}{l}\text { Carbon monoxide } \\
\text { Concentration }\end{array}$ & $\begin{array}{l}C \\
C^{+}\end{array}$ \\
\hline $\begin{array}{l}\text { Silvani Street } \\
\text { (35 m a.g.1.) }\end{array}$ & $\begin{array}{l}\text { Cup and vane } \\
\text { Anemometer WMS301, } \\
\text { Thermohygrometer } \\
\text { HMP230 }\end{array}$ & $\begin{array}{l}30 \text { min } \\
\text { (average) } \\
30 \text { min } \\
\text { (average) }\end{array}$ & $\begin{array}{l}\text { Wind speed } \\
\text { and direction } \\
\text { Air temperature }\end{array}$ & $\begin{array}{l}U_{b}, U_{b}^{m} \\
\Delta U_{b}, \mathrm{~B} \\
\theta_{b}, T_{a} \\
\Delta \theta_{b}, \Delta T^{m}\end{array}$ \\
\hline $\begin{array}{l}\text { Asinelli Tower } \\
\text { (100 m a.g.l.) }\end{array}$ & $\begin{array}{l}\text { Cup (Vv20) and vane } \\
\text { (Dv20) anemometer, } \\
\text { Thermohygrometer } \\
\text { THS }\end{array}$ & $\begin{array}{l}60 \mathrm{~min} \\
\text { (average) } \\
60 \mathrm{~min} \\
\text { (average) }\end{array}$ & $\begin{array}{l}\text { Wind speed } \\
\text { Direction } \\
\text { Air temperature }\end{array}$ & $\begin{array}{l}U_{b} \\
\Delta U_{b} \\
\theta_{b} \\
\Delta \theta_{b}\end{array}$ \\
\hline
\end{tabular}

\section{Data Processing}

\subsection{Despiking and Rotation}

Datasets were preliminary checked to detect and remove non-physical data or instrumental failures. Thresholds for data removal are defined on the basis of typical local ranges, so that the velocity components $|(u, v, w)|<20 \mathrm{~m} \mathrm{~s}^{-1}$, while temperature (both sonic and real) $|T|<50^{\circ} \mathrm{C}$. Values above thresholds are replaced with the nearest finite value along the time series. The same procedure is applied to not-a-number and infinite values. If the number of "wrong values" exceeds $50 \%$ of the data within the averaging period ( $5 \mathrm{~min})$, they are simply replaced with non-values and the interval is rejected. Sonic data are then despiked, following a procedure similar to the method proposed by Højstrup (1993), based on the assumption that each interval within the dataset is a Gaussian distribution of independent data for which 
the mean $\bar{x}$ and the standard deviation $\sigma$ are calculated. Values above a certain threshold $(K \sigma)$ are marked as spikes, with the discriminant factor $K=3.5$ selected following both Vickers and Mahrt (1997) and Schmid et al. (2000). The interval duration is 5 min (Vickers and Mahrt 1997), which ensures that most of the variance is gathered without violating the Gaussian assumption. The despiking procedure is only applied once per interval and spikes are replaced with the mean value of the interval calculated without the spike.

The despiked horizontal velocity components are rotated following McMillen (1988) to align the velocity vector to the streamline. Once data are despiked and rotated, both meanflow quantities and kinematic turbulent fluxes are computed at all levels inside and above the canyon. To ensure a general robustness of the analysis without losing small-scale processes, all quantities have been averaged in time over a period of $5 \mathrm{~min}$.

\subsection{Pollutant Source and Normalization}

Given that the field experiment was conducted using the existing traffic source (i.e. with no control on the emissions), a specific procedure was developed to untangle concentration from emissions for further use in the analysis. This approach enables the minimization of the source contribution to the measured pollutant concentrations. To minimize the impact of additional sources other than the traffic-related one, we use the carbon monoxide $\mathrm{CO}$ as the local passive tracer. Traffic counts are obtained from counting stations based on inductive-loop technology located at the main traffic junctions within the city. We derived the traffic rate $T_{r}\left(\mathrm{~min}^{-1}\right)$ from the traffic counts as the number of vehicles passing throughout the street per minute. The traffic rate gives a clear footprint on pollutant concentrations, as shown in Fig. 3a, where the $\mathrm{CO}$ concentrations $C\left(\mathrm{mg} \mathrm{m}^{-3}\right)$ are shown along with the traffic rate through Marconi Street.

Low traffic rates are measured during night-time. During daytime, the heavy activity of buses largely affects emissions. As a consequence, traffic rates only slowly decrease after the morning rush hour until the night-time cutoff. Evening rush hours have been detected



Fig. 3 5-min-averaged CO concentration (blue line) compared with the a traffic rate $T_{r}$ (red line), b wind speed at the rooftop level $U_{H}$ (green line), and c emission source rate $Q_{e}$ (purple line). d Normalized CO concentration $C^{+}$(black line). The shadowed areas highlight night-time periods. On average, the sun rises at 0600 and sets at $1800($ UTC+1) 
only during the first two days of the analyzed period. The general trend of $\mathrm{CO}$ concentration shows a good agreement with traffic data as expected, since $\mathrm{CO}$ is considered a criterion for estimating pollutants emitted by internal combustion engines (Winkler et al. 2018). The morning rush hour is highlighted by the steep increase in $\mathrm{CO}$ concentrations. At night, $\mathrm{CO}$ concentrations drop to the background value as the traffic rate falls. Nevertheless, $\mathrm{CO}$ concentrations rapidly increase in correspondence with a supposed evening rush hour, which is not always reflected in the traffic signal. This different behaviour can be linked to the trafficfleet composition affecting the emissions, or to local mixing processes within the canyon and external flow intensity, which can enhance or reduce the pollutant removal (Murena and Favale 2007). While the pollutant-source rate $Q_{e}\left(\mathrm{~g} \mathrm{~s}^{-1}\right)$ has a similar footprint to the traffic rate on the $\mathrm{CO}$ concentrations (Fig. 3c), the mean wind speed measured at the canyon rooftop $U_{H}$ is shown to modulate the $\mathrm{CO}$ removal. In particular, $\mathrm{CO}$ concentrations are found to be inversely correlated with the wind speed (Fig. 3b). To remove local emission-rate variability and mean-flow dependency while accounting for canyon geometry (Kubilay et al. 2017), the measured CO concentrations are normalized with a reference value $C_{0}\left(\mathrm{mg} \mathrm{m}^{-3}\right)$ defined as

$$
C_{0}=\frac{Q_{e}}{H W U_{H}} .
$$

An algorithm has been developed to estimate the pollutant-source rate $Q_{e}$. Traffic-related emissions are derived by classifying the traffic rate by vehicle type, whereby vehicles, buses, and Euro ${ }^{2}$ technology are further subdivided according to their fuel-type. The number of buses passing through Marconi Street is directly taken from the bus schedule of the Bologna municipality. ${ }^{3}$ The local fleet composition is then extracted from the regional inventory of circulating vehicles ${ }^{4}$ and is used to disaggregate the differences between the vehicular traffic and the number of buses into the previous classification for each vehicular type. Pollutantemission rates $\left(\mathrm{g} \mathrm{km}^{-1}\right)$ are then estimated using the European Monitoring and Evaluation Program of the European Environment Agency (EMEP/EEA) air pollutant emission inventory for each vehicle category (European Environment Agency 2016). Finally, the pollutant-source rate $Q_{e}$ is calculated from pollutant emissions using a representative vehicle urban speed of $19 \mathrm{~km} \mathrm{~h}^{-1}$ (European Environment Agency 2016) as a factor to convert $Q_{e}$ into the units of $\mathrm{g} \mathrm{s}^{-1}$. Once all the terms of Eq. 6 are defined, normalized $\mathrm{CO}$ concentrations, named $C^{+}$, simply result from the ratio between the measured concentrations in the street canyon and the reference concentration $C_{0}$ (Fig. 3d). The behaviour of the normalized concentration $C^{+}$is completely different from the measured $\mathrm{CO}$ concentration. The source rate and backgroundflow dependencies are removed. As expected, the normalized concentrations $\mathrm{C}^{+}$are smaller during daytime than night-time, owing to local mixing within the canopy and the atmospheric stratification above (Li et al. 2015, 2016).

To prove the independence of the resulting $\mathrm{C}^{+}$concentrations on the normalizing factors, a simple least-squares linear-regression method is used to search possible linear correlations between $C^{+}$and the inverse of the rate $Q_{e}$ (Fig. 4a), and the wind speed $U_{H}$ (Fig. 4b). A coefficient of determination is then retrieved for both regressions and directly reported in the panels of Fig. 4, showing very poor correlations in both cases. Therefore, the normalized concentrations $\mathrm{C}^{+}$are assumed to be dependent only on local circulations, with transport governed by turbulent processes. As a consequence, the normalized concentrations $C^{+}$are

\footnotetext{
2 European emissions regulations for light-duty vehicles.

3 Available on the website of the regional transport company at https://www.tper.it/.

4 Available at the Italian Car Club website (http://www.aci.it/laci/studi-e-ricerche/dati-e-statistiche/opendata.html).
} 



Fig. 4 Normalized $\mathrm{CO}$ concentration $\mathrm{C}^{+}$as a function of, a the inverse of the emission rate $Q_{e}$, and $\mathbf{b}$ the wind speed at the canyon rooftop $U_{H}$. The black lines represent the linear regressions of the data with the respective equations, while $R^{2}$ is the coefficient of determination

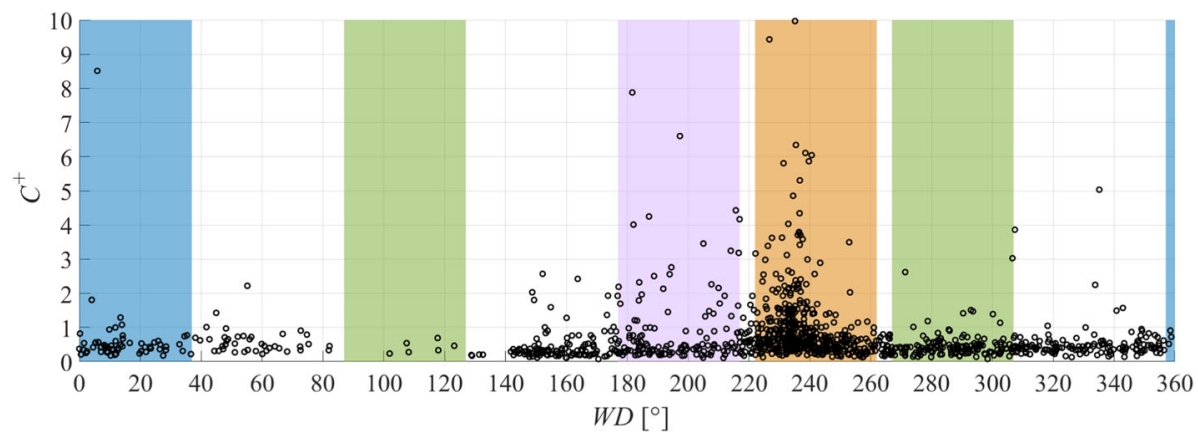

Fig. 5 5-min-averaged normalized concentration $C^{+}$as a function of the wind direction $W D$. The shadowed areas highlight the different background wind directions with respect to the canyon orientation, where north parallel is shaded in blue, south parallel in purple, perpendicular in green, and south-west in orange

expected to change according to the atmospheric factors that drive the evolution of the local circulation. Specifically, as the flow within the canyon is a function of the background wind direction, normalized concentrations $C^{+}$are supposed to show a similar dependency.

Figure 5 displays the normalized concentration variation as a function of the background wind direction. The normalized concentrations are small for the north parallel and perpendicular wind directions, and larger for the south-west case. The majority of the $C^{+}$values for the south parallel wind direction are as low as for the north parallel and perpendicular cases, but several large concentration values are retrieved as well.

\section{Results and Discussion}

\subsection{Overview of the Flow and Turbulence Characteristics}

Large urban environments perturb the large-scale flow. Figure 6 provides an insight to the wind speed and direction together with air temperature during the analyzed period. Data from Asinelli Tower, Silvani Street, and the Marconi Street rooftop level are used to characterize the mean flow (Fig. 2). Temperature signals in Fig. 6c show the typical diurnal behaviour, 




Fig. 6 1-h averaged wind speed (a), wind direction (b) and temperature (c) measured above the canopy layer. Colours indicate the measurement sites: Asinelli Tower at $100 \mathrm{~m}$ (in magenta) a.g.l., Silvani street at $35 \mathrm{~m}$ a.g.l. (in cyan) and Marconi street rooftop at $33 \mathrm{~m}$ a.g.l. (in green). The shadowed areas highlight night-time periods, as for Fig. 3

reaching maximum values at 1600-1700 UTC+1, and the nocturnal inversion. Wind speeds in the roughness layer (green dots in Fig. 6a) are constantly small, i.e. below $5 \mathrm{~m} \mathrm{~s}^{-1}$. Finally, wind directions in Fig. $6 \mathrm{~b}$ are typical of a thermal circulation. A well-defined downslope/downvalley flow from the southern hill chain (southerly parallel and south-westerly oblique background wind direction to the canyon orientation) is detected during nights, while an upslope/upvalley flow from the northern plain (northerly parallel background wind direction to the canyon orientation) is the predominant diurnal flow. Common daytime conditions also correspond to wind directions perpendicular to the street canyon. This evolution of the background flow necessitates the investigation of different wind directions.

During low background wind speeds, the local canopy circulation is driven and sustained by the turbulent fluxes. Figures 7 and 8 show the evolution of both kinematic momentum and heat fluxes measured inside and at the canyon rooftop. At the rooftop level, fluxes are influenced by the local mean flow. Momentum fluxes inside the canyon are generally smaller than at the rooftop due to the morphological constraint on the mean flow. Conversely, the heat fluxes inside the canyon are strengthened by the presence of multiple artificial surfaces prone to release sensible heat during both daytime and night-time. According to Fig. 6a, as the wind speed always increases with height, the momentum flux $\overline{w^{\prime} u^{\prime}}$ at the rooftop level should be negative, as observed in Fig. 7. However, the flux magnitude does not scale directly with the vertical variation of the background wind speed. The vertical kinematic heat flux $\overline{w^{\prime} \theta^{\prime}}$ at the rooftop level is expected to change sign according to the temperature gradient. Again, the rooftop-level flux (Fig. 8) appears to be decoupled from the atmosphere above, since the value of the heat flux $\overline{w^{\prime} \theta^{\prime}}$ is almost always positive. These behaviours suggest that mechanical and thermal exchange are driven by the local momentum and heat transport through the shear layer rather than by the large-scale gradients. 


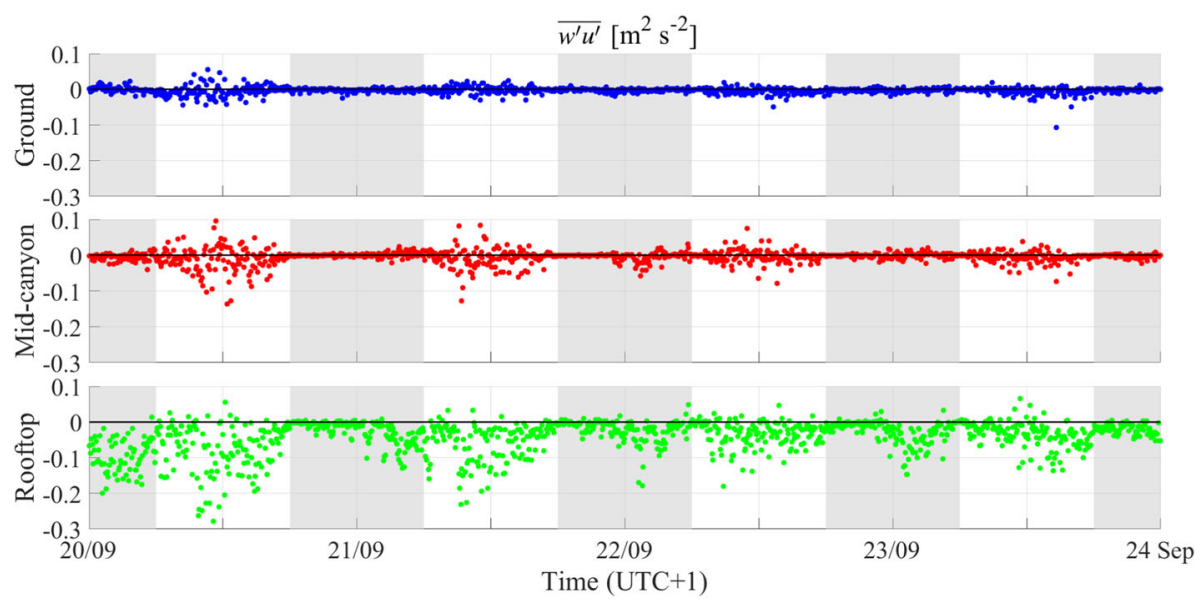

Fig. 7 5-min averaged kinematic momentum fluxes $\overline{w^{\prime} u^{\prime}}$ at ground (blue), mid-canyon (red), and rooftop (green) levels in Marconi Street. The shadowed areas highlight night-time periods, as for Fig. 3. The black lines identify the zero value

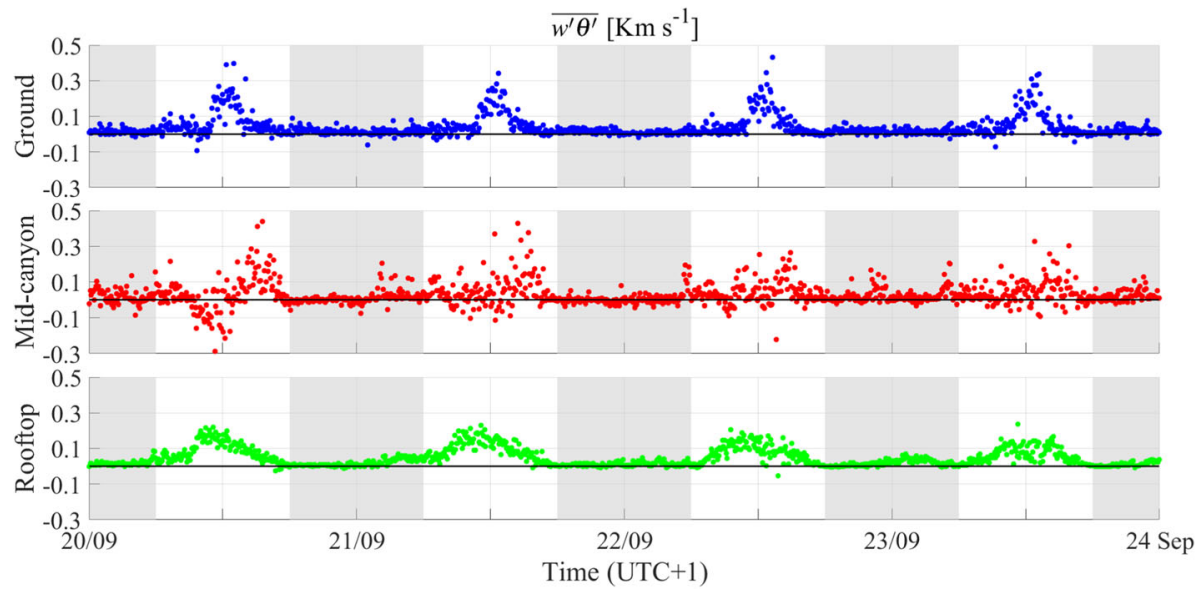

Fig. 8 5-min averaged kinematic heat fluxes $\overline{w^{\prime} \theta^{\prime}}$ at ground (blue), mid-canyon (red), and rooftop (green) levels in Marconi Street. The shadowed areas highlight night-time periods, as for Fig. 3. The black lines identify the zero value

\subsection{Evaluation of Time Scales}

Time scales derived in Sect. 2 are estimated from the measured data of Marconi Street during the whole analyzed period (20-23 September 2017), using Eq. 2 at the rooftop level, and Eq. 4 inside the canyon (ground and mid-canyon levels). Figure 9 shows the density distributions of both time scales at each level, computed from the 5-min averaged data. So far, no winddirection filter has been applied. Time-scale distributions in Fig. 9 reveal similar shapes, with maximum occurrences within the first three bins and exponential-like decreases at larger values. Both time scales are skewed toward zero because mixing dominates inside and above the canyon. Time-scale distributions can be approximated by the generalized extreme 



Fig. 9 Density distributions of mechanical $\tau_{d}$ (a) and thermal $\tau_{h}(\mathbf{b})$ time scales and respective GEV functions retrieved at the ground (blue), mid-canyon (red), and rooftop (green) levels of Marconi Street during the analyzed period (20-23 September 2017). The bin size is 500 s. The retrieved modes are reported in Table 2 (see the overall column)

value (GEV) functions. Although the common application of these functions for atmospheric processes is often limited to the study of extreme events, it can be extended to more general asymmetrical "tailed distributions" (Kotz and Nadarajah 2000), as in the current case. The extrapolated GEV functions enable a better comparison of time scales for the different levels and for different background wind directions. The mode of each function gives an estimation of the momentum and heat exchange time, i.e., the mixing time of an atmospheric layer. The shape and tail length of the distributions are instead a good evaluation of the mixing-time variability.

The extrapolated GEV functions are superimposed to the time-scale distributions in Fig. 9, and the modes are reported in Table 2. Both time-scale modes decrease from the groundlevel to the rooftop-level distributions. The behaviour of the mechanical time scale $\tau_{d}$ is a direct consequence of the flux evolution (Fig. 7), since momentum transport is larger at the rooftop level than inside the canyon. The momentum flux at the ground can be strongly inhibited by the mechanical friction of the surface and obstacle roughness (Kastner-Klein and Rotach 2004), enhancing the momentum time-scale mode to almost twice the rooftop one and shifting the distribution towards larger values (Fig. 9a, ground level). The thermal time scale $\tau_{h}$ is more self consistent, though the heat fluxes inside the canyon can overpower the heat fluxes at the rooftop, since the differential heating of building facades during the

Table 2 Time-scale modes retrieved from the respective GEV functions for the whole period (Overall) and different wind directions Units of seconds

\begin{tabular}{|c|c|c|c|c|c|c|}
\hline & Level & Overall & $\begin{array}{l}\text { North } \\
\text { Parallel }\end{array}$ & $\begin{array}{l}\text { South } \\
\text { Parallel }\end{array}$ & Perpendicular & South-west \\
\hline \multirow[t]{3}{*}{$\tau_{d}$} & Ground & $570 \pm 60$ & $320 \pm 30$ & $980 \pm 100$ & $540 \pm 50$ & $540 \pm 50$ \\
\hline & Mid-canyon & $420 \pm 40$ & $320 \pm 30$ & $730 \pm 70$ & $320 \pm 30$ & $530 \pm 50$ \\
\hline & Rooftop & $310 \pm 30$ & $420 \pm 40$ & $1100 \pm 100$ & $210 \pm 20$ & $120 \pm 10$ \\
\hline \multirow[t]{3}{*}{$\tau_{h}$} & Ground & $310 \pm 30$ & $200 \pm 20$ & $300 \pm 30$ & $200 \pm 20$ & $470 \pm 50$ \\
\hline & Mid-canyon & $300 \pm 30$ & $180 \pm 20$ & $190 \pm 20$ & $190 \pm 20$ & $470 \pm 50$ \\
\hline & Rooftop & $300 \pm 30$ & $220 \pm 20$ & $610 \pm 60$ & $220 \pm 20$ & $520 \pm 50$ \\
\hline
\end{tabular}



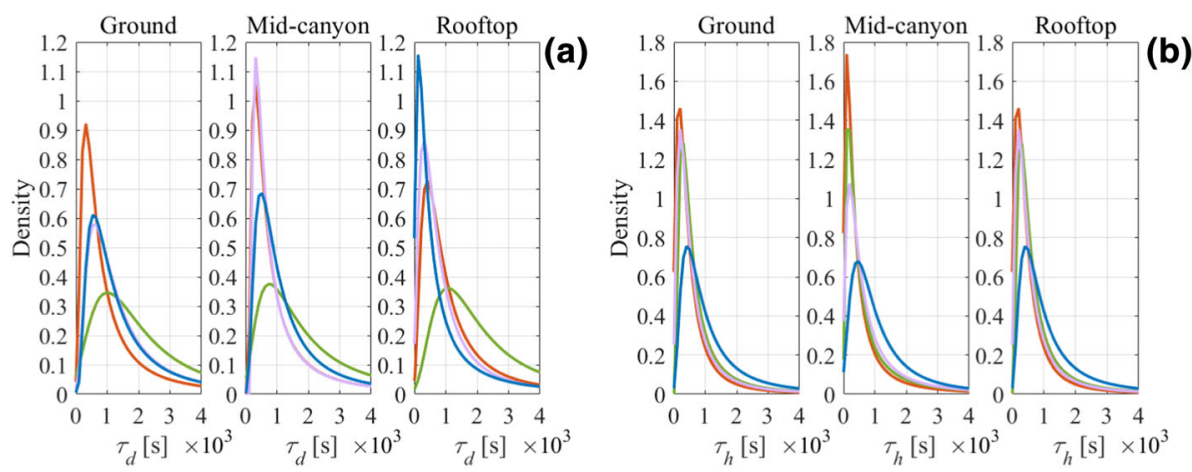

Fig. 10 Generalized extreme value functions of the mechanical $\tau_{d}$ (a) and thermal $\tau_{h}$ (b) time scales for each background wind direction (north parallel is displayed in blue, south parallel in purple, perpendicular in green, and south-west in orange) retrieved ground, mid-canyon, and rooftop levels of Marconi Street during the analyzed period (20-23 September 2017). The retrieved modes are reported in Table 2

day (Cheng et al. 2009b) and the heat release from the street surface (Li et al. 2012) can contribute as additional heat sources, increasing vertical transport and mixing, and reducing the magnitude of the time scale. This mixed condition persists during night-time (Fig. 8), reducing the spread of the ground and mid-canyon level distributions (Fig. 9b). On the basis of the overall values reported in thermal-exchange processes inside the canyon are faster than the mechanical ones.

The analysis of time scales is also performed after classifying data by the wind-direction ranges defined in Sect. 3. The extrapolated GEV distributions for each wind direction are displayed in Fig. 10 and the respective modes are reported in Table 2 (north parallel, south parallel, perpendicular, and south-west columns). The distributions of the mechanical time scale $\tau_{d}$ (Fig. 10a) are wider and shifted toward larger values than the equivalent distributions of the thermal time scale $\tau_{h}$ (Fig. 10b). The spread of the mechanical time-scale distributions is particularly evident for the south parallel wind direction, whose modes describe very slow mixing conditions. Fast mixing is obtained at the rooftop level when the background wind direction is perpendicular or oblique to the canyon, but momentum exchange is lower within the canyon where the mixing time increases. An opposite behaviour is detected with parallel wind directions, where mixing within the canyon is greater than at the rooftop. The thermal time scales $\tau_{h}$ are again more self consistent. The air column is well mixed from the rooftop to the ground level by the turbulent transport and the heat release from surfaces. Therefore, the whole canyon is characterized by the same heat exchange velocity, especially for the north parallel and the perpendicular wind directions, while low mixing is found for the south-west and at the rooftop of the south parallel case.

Modes of the mechanical time scale obtained for the perpendicular background wind direction can be compared with previously reported recirculation and pollutant-removal times. The vortex recirculation time $T=H / u_{*}$ is generally used in computational fluid dynamics to identify the time scale of turbulent motion in the street canyon, and ranges between 90 and $490 \mathrm{~s}$, with a mean value of $200 \mathrm{~s}$, in agreement with other results obtained by our research group (private communication). The mode of the mechanical time scale evaluated at the rooftop level $\left(\tau_{d}^{H, p}=210 \mathrm{~s}\right)$ is also in agreement with the pollutant removal time $T=200 \mathrm{~s}$ reported by Salizzoni et al. (2009) and computed with the current investigation parameters. This result also aligns with the Lagrangian time scales reported by Lo and Ngan (2017), ranging between $198 \mathrm{~s}$ and $269 \mathrm{~s}$. 


\subsection{Evaluation of Exchange Rates}

Equation 5 describes the turbulent mixing and transport rates inside the canyon, considering separately mechanical and thermal processes, for which an exchange rate $\eta<1$ describes an advantageous condition for momentum and heat transport and exchange with the free atmosphere. Conversely, when the rates $\eta>1$, mixing inside the canyon is less efficient and air is trapped within the canopy. To strengthen the robustness of the analysis, the exchange rates $\eta$ are averaged over 30-min intervals, and are referred to the ground level when calculated as ratios between the time scales at the rooftop and ground levels, or to the mid-canyon level when the ratios include the time scales at the rooftop and mid-canyon levels. Distributions of the exchange rates $\eta$ have been computed according to the wind-direction classification and approximated through the GEV functions, as performed for the time scales in Figs. 9 and 10. The modes of the GEV functions are presented in Table 3. As retrieved for the time scales, the exchange rates are affected by the different circulations developing for each wind direction, which leads to a different efficacy of the canyon mixing. The south parallel condition is the most favourable for exchange processes due to the large value of the time scales at the rooftop level (see Table 2). A good efficiency is also shown for perpendicular and north parallel wind directions, while the south-west highlights a very disadvantageous scenario where exchange is almost always suppressed. Definitively, different background wind directions drive different mixing times and exchange efficacy.

\subsection{Pollutant-Removal Efficacy and Generalization to Different Aspect Ratios}

As a consequence of the variation of the mixing properties within and above the street canyon, pollutant concentrations are also affected. Under the assumption of mass transport behaving as momentum and heat transport, exchange rates are expected to regulate the levels of the normalized concentration $C^{+}$within the canyon, depending on the most effective in-canyon circulation. To discern the importance of the inertial circulation over the thermal one, a specific buoyancy parameter $B$ has been introduced by Dallman et al. (2014) as the ratio between horizontal buoyancy and background wind speed,

$$
B=\frac{g \alpha H \Delta T}{U_{b}^{2}\left(1+\left(\frac{H}{D}\right)^{2}\right)},
$$

where $g$ is the acceleration due to gravity, $\alpha\left(\mathrm{K}^{-1}\right)$ is the thermal expansion coefficient, $U_{b}$ is the background wind speed, $\Delta T=T_{1, m}-T_{2, m}$ is the horizontal temperature difference between the air temperature measured at the opposite canyon sides $\left(T_{1, m}\right.$ measured at the

Table 3 Exchange-rate modes retrieved from the respective GEV functions for the whole period (Overall) and different wind directions

\begin{tabular}{lllllll}
\hline \multicolumn{2}{l}{ Level } & Overall & $\begin{array}{l}\text { North } \\
\text { Parallel }\end{array}$ & $\begin{array}{l}\text { South } \\
\text { Parallel }\end{array}$ & Perpendicular & South-west \\
\hline$\eta_{d}$ & Ground & $0.42 \pm 0.04$ & $0.46 \pm 0.05$ & $0.28 \pm 0.03$ & $0.41 \pm 0.04$ & $2.5 \pm 0.3$ \\
& Mid-canyon & $0.39 \pm 0.04$ & $0.38 \pm 0.04$ & $0.24 \pm 0.02$ & $0.29 \pm 0.03$ & $1.9 \pm 0.2$ \\
$\eta_{h}$ & Ground & $0.39 \pm 0.04$ & $0.47 \pm 0.05$ & $0.23 \pm 0.02$ & $0.25 \pm 0.03$ & $1.6 \pm 0.2$ \\
& Mid-canyon & $0.38 \pm 0.04$ & $0.51 \pm 0.05$ & $0.20 \pm 0.02$ & $0.26 \pm 0.03$ & $1.6 \pm 0.2$ \\
\hline
\end{tabular}





Fig. 11 a Evolution of the buoyancy parameter $B$ as defined in Eq. 7. The dashed line highlights the critical value $B_{c}$. The shaded areas highlight night-time periods, as for Fig. 3. b Wind-speed ratio $U_{m a} / U_{b}$ as a function of the buoyancy parameter $B$. Displayed values are bin-averaged and the errorbars represent the standard deviation in each bin. Dashed lines are the measurement trends according to Eq. 8 referring to the present field results in blue. Data in black are retrieved from Dallman et al. (2014). Data in red are the present field results scaled according to Eq. 9

ground level, $T_{2, m}$ at the mid-canyon one), and $D$ is the distance between the mid-canyon and ground levels. Equation 7 is calculated for the whole period and compared to its critical value $B_{c}$ (Fig. 11a), defined as the threshold separating inertial and thermal-circulation regimes. To estimate the value of $B_{c}$, the wind-speed ratio $U_{m a} / U_{b}$ (i.e. the ratio between the canyonaveraged $U_{m a}$ and the background $U_{b}$ wind speeds) is displayed as a function of the buoyancy parameter $B$ in Fig. 11b.

The wind-speed ratio is supposed to be constant with the buoyancy parameter $B$ as long as the circulation is inertial, meaning that the in-canyon velocity scales directly with the background one. Circulation becomes thermal when this ratio starts depending on the buoyancy parameter $B$. From the trends in Fig. 11b, we model the wind-speed ratio as

$$
\frac{U_{m a}}{U_{b}} \sim \begin{cases}C_{1} & \text { if } B<B_{c} \\ C_{2} B^{1 / 2} & \text { if } B>B_{c},\end{cases}
$$

where the constants $C_{1}=0.2$ and $C_{2}=0.41$ are computed from Fig. $11 \mathrm{~b}$. The intersection between the trends in Fig. $11 \mathrm{~b}$ gives the critical value $B_{c} \approx 0.06$. Note that a negative bias exists between the present field results (blue circles in Fig. 11b) and those obtained by Dallman et al. (2014) (full black squares in Fig. 11b) because of the different aspect ratios of the investigated canyon $(H / W=0.66)$ in Dallman et al. (2014) with respect to the value of the present study $(H / W \approx 1.65)$. This is justified considering that the wind-speed ratio is a decreasing function of the aspect ratio when $H / W>0.5$ (Soulhac et al. 2008). As further noted by Solazzo and Britter (2007), the temperature inside the canyon depends on the aspect ratio. To enhance the comparison with the Dallman et al. (2014) data, two scalings are proposed

$$
\begin{aligned}
\frac{U_{m a}^{m}}{U_{b}^{m}} & =\frac{H}{W} \frac{W_{D a}}{H_{D a}} \frac{U_{m a}}{U_{b}}, \\
\Delta T^{m} & =\left(0.22 \frac{H_{D a}}{W_{D a}}-2\right)\left(T_{\Delta, m}-T_{a}\right) .
\end{aligned}
$$

Equation 9a is the rescaling of the wind-speed ratio according to the aspect ratios of the two studies. Within Eq. 9a, $U_{m a}^{m} / U_{b}^{m}$ is the modified wind-speed ratio $U_{m a} / U_{b}$, while $W_{D a}$ and 

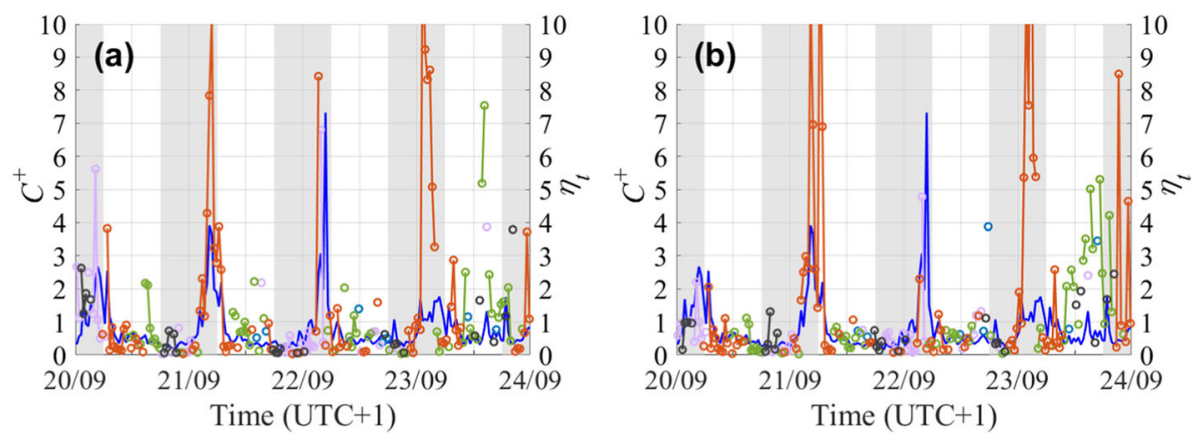

Fig. 12 Comparison between the normalized concentration $C^{+}$and the total exchange rate $\eta_{t}$ for a the rooftop to ground level and $\mathbf{b}$ the rooftop to mid-canyon level exchange rates. The continuous blue line refers to the $\mathrm{C}^{+}$concentration, coloured lines with markers refer to the total exchange rate $\eta_{t}$ following the wind-direction classification (north parallel displayed in light blue, south parallel in purple, perpendicular in green, south-west in orange, and the remaining sectors in black). The shadowed areas highlight night-time periods, as for Fig. 3

$H_{D a}$ are the mean width and height of the studied canyon in Dallman et al. (2014). Equation 9b computes the air temperature difference between opposite building facades as a function of the aspect ratio, modifying the previous parametrization by Solazzo and Britter (2007). Within Eq. $9 \mathrm{~b}, \Delta T^{m}$ is the modified horizontal temperature difference $\Delta T$, and $T_{a}(\mathrm{~K})$ is the ambient temperature measured outside the canopy at Silvani Street. The numerical coefficients are retrieved from Solazzo and Britter (2007). This modified horizontal temperature difference $\Delta T^{m}$ is then inserted into Eq. 7 to calculate a scaled buoyancy parameter $B^{m}$. Figure $11 \mathrm{~b}$ shows good agreement between the scaled field results (red circles) and the Dallman et al. (2014) data (full black squares), confirming that the relation between the parameters $U_{m a} / U_{b}$ and $B$ holds as expected despite the different aspect ratios.

As long as $B>B_{c}$, the circulation within the canyon is thermally driven and the rate $\eta_{h}$ is the dominant exchange rate. When $B \leq B_{c}$, the circulation becomes inertial, with the rate $\eta_{d}$ as the dominant exchange rate. The inertial circulation is found to be predominant over the thermal one, the first being observed during $83 \%$ of the analyzed period with $17 \%$ for the latter. Specifically, the thermal circulation is only detected during the late afternoon (Fig. 11a), when the differential solar radiation at opposite building facades causes a horizontal temperature gradient between them. For the same reason, thermal circulation is also expected in the early morning, but the residual nocturnal flow preserves the inertial circulation (see Fig. 6a). To account for both mechanical and thermal processes, a new total exchange rate $\eta_{t}$ is defined as

$$
\eta_{t}= \begin{cases}\eta_{d} & \text { if } B<B_{c} \\ \eta_{h} & \text { if } B>B_{c}\end{cases}
$$

The time series obtained from Eq. 10 at ground and mid-canyon levels are compared to the normalized concentrations $C^{+}$in Fig. 12, with the total exchange rate $\eta_{t}$ following the diurnal path of $C^{+}$, especially during the first three days, with a maximum at sunrise and a minimum during the early night.

The discrepancy observed during the last day can be associated with the long-lasting predominance of the thermal circulation during the daytime, not present in the previous days. Peaks of the normalized concentrations occur when the buoyancy parameter $B$ is close 
to its critical value $B_{c}$, i.e., when no predominant circulation is present within the canyon so that exchange processes are equally important (Dallman et al. 2014). When the circulation is well established $\left(B \gg B_{c}\right.$ or $B \ll B_{c}$ ), the normalized concentrations are small and well described by the total exchange rate $\eta_{t}$. The contribution of each wind direction is also evident. The large values of $\eta_{t}$ observed for the south-west direction match the diurnal peaks of $\mathrm{C}^{+}$concentrations, which is a signature of inefficient exchange causing pollutant accumulation. Pollutant removal increases for north parallel and perpendicular directions in accordance with the decrease in $\eta_{t}$ values. For south parallel wind directions, disadvantageous and advantageous exchange rates are observed, with both providing a good agreement with the $C^{+}$signal. It can be concluded that exchange processes analyzed in terms of inertial and thermal circulations provide a direct approach to asses the variation of passive pollutant concentrations within an urban canopy.

\section{Conclusions}

Exchange processes between the urban canopy layer and the atmosphere above have been investigated to characterize the combined effects of mechanical and thermal processes in a real urban street canyon. To unveil the complexity of mechanical and thermal interactions with the canyon circulation, an intensive experimental field campaign was designed to study the turbulent exchange processes under weak synoptic conditions. Specifically, a street canyon named Marconi Street, with a mean aspect ratio $H / W$ of 1.65 , has been chosen within the business core of Bologna city centre (Italy) to be the main site of the field investigation. High-resolution instrumentation has been installed at three different levels within and above the canyon to detail the atmospheric flow and turbulent fields. Roadside air-quality measurements within the canyon and supporting meteorological stations in the city completed the experimental design. Well-known processing techniques have been used to pre-process fast-sampled data.

To quantify the mixing caused by mechanical and thermal exchange within different streetcanyon layers, the Buckingham theorem is used to derive new diagnostic quantities specific to either mechanical or thermal process. Specifically, time scales define the time required to generate mixing within different canyon layers owing to momentum and heat exchange, with smaller time scales resulting in more rapid mixing. Exchange rates are then evaluated as ratios between the time scales within the canopy and that at the rooftop level to estimate the momentum and heat exchange factors between the canopy and the atmosphere above. As long as these factors are smaller than one, momentum and heat exchange are faster within the canopy, favouring mixing from the ground to the canyon top. Thus, exchange rates are a measure of the transport efficacy from the canopy to the atmosphere above.

Given that homogeneous mixing does not always occur within the canyon and that background-flow directions may affect the in-canyon processes, these diagnostic quantities have been estimated at different levels according to different wind directions. Mechanical processes are found to vary within and above the canopy, describing rapid mixing at the canyon rooftop level and efficient exchange under different wind directions. Thermal processes are found to be even more rapid than mechanical processes, leading to more homogeneous mixing in the canopy, and are specifically efficient for perpendicular wind directions. Both mechanical and thermal processes are found to be inefficient under oblique wind directions.

The exchange rates have been proven to regulate the pollutant-concentration variability within the canopy when the effect of local emissions has been removed. The analysis also 
shows that exchange processes are not effective in pollutant removal in the presence of oblique wind directions. To demarcate the importance of mechanical and thermal processes in causing mixing, an evaluation of the local-circulation regime has been introduced. The buoyancy parameter proposed by Dallman et al. (2014) has been used to discern the inertial and thermal circulation regime within the canopy. For the present study, a larger incidence of the first (with a frequency of $83 \%$ over the entire period) occurred over the second. Using this approach, simple parametrizations have been introduced to generalize the quantification of the flow characteristics, thus extending the current findings to different street-canyon aspect ratios.

The methodology discussed here, as well as the diagnostic quantities introduced, allow for the analysis of field data in view of a fast assessment of the ventilation conditions within urban canyons and the likely occurrence of pollution hot-spots.

Acknowledgements Open access funding provided by Alma Mater Studiorum - Università di Bologna within the CRUI-CARE Agreement. This research has been supported by the iSCAPE (Improving the Smart Control of Air Pollution in Europe) project funded by the European Community's H2020 Programme (H2020-SC504-2015) under the Grant Agreement No.689954 (https://www.iscapeproject.eu/). The authors are pleased to acknowledge all the academics, researchers, specialists and students from the Department of Physics and Astronomy and the Department of Industrial Engineering of the University of Bologna, the ARPAE and the National Research Council (CNR) for their tremendous effort dedicated to the realization of the experimental field campaign. Particularly, we express sincere gratitude to Carla Barbieri and Luca Torreggiani from ARPAE for the deployment and maintenance during the whole period of the instrumentation for air-quality measurements and their active collaboration to realize the experimental design. We also acknowledge Marianna Nardino from CNR for the deployment and installation of part of the instrumentation for the measurement of turbulence. We acknowledge all members of the research group, particularly Beatrice Pulvirenti from the Department of Industrial Engineering of the University of Bologna, Marco Deserti from Regione EmiliaRomagna and Enrico Minguzzi from ARPAE for all the support given during the realization of the campaign and the fruitful discussions. Special gratitude is given to Massimo Bacchetti (technical support for research at the Department of Physics and Astronomy) for the setting of the station mountings, the field installations and local instrument maintenance during the whole campaign. We sincerely acknowledge the Municipality of Bologna for granting the possibility to deploy the experiments in the city centre, the CGIL (Confederazione Generale Italiana del Lavoro) and private citizens for having hosted part of the instrumentation on private balconies and rooftops. Finally, we acknowledge the suggestions made by three anonymous referees, which have helped us to improve the manuscript substantially.

Open Access This article is licensed under a Creative Commons Attribution 4.0 International License, which permits use, sharing, adaptation, distribution and reproduction in any medium or format, as long as you give appropriate credit to the original author(s) and the source, provide a link to the Creative Commons licence, and indicate if changes were made. The images or other third party material in this article are included in the article's Creative Commons licence, unless indicated otherwise in a credit line to the material. If material is not included in the article's Creative Commons licence and your intended use is not permitted by statutory regulation or exceeds the permitted use, you will need to obtain permission directly from the copyright holder. To view a copy of this licence, visit http://creativecommons.org/licenses/by/4.0/.

\section{Appendix 1: Application of the Buckingham Theorem}

The Buckingham theorem is applied to evaluate the time scale $\tau_{d}^{H}$. The same computation is then used for the other time scales extrapolated in Sect. 2. Equation 1a states that

$$
\tau_{d}^{H}=f\left(\left.\overline{w^{\prime} u^{\prime}}\right|_{H}, H, L, W, \frac{\Delta U_{b}}{\Delta z}\right) .
$$

The dimensional analysis is performed for each term, so that

$$
\left[\tau_{d}^{H}\right]=\mathrm{s},
$$




$$
\begin{aligned}
& {\left[\left.\overline{w^{\prime} u^{\prime}}\right|_{H}\right]=\mathrm{m}^{2} \mathrm{~s}^{-2},} \\
& {[H]=\mathrm{m},} \\
& {[L]=\mathrm{m},} \\
& {[W]=\mathrm{m},} \\
& {\left[\frac{\Delta U_{b}}{\Delta z}\right]=\mathrm{s}^{-1} .}
\end{aligned}
$$

The theorem states that the product of the variable dimensions on the right-hand side of Eq. 11 powered to real coefficients must be equal to the actual dimension of the term on the left of the same equation. Therefore,

$$
\begin{aligned}
& \mathrm{s}^{1}=\left(\mathrm{m}^{2} \mathrm{~s}^{-2}\right)^{a}(\mathrm{~m})^{b}(\mathrm{~m})^{c}(\mathrm{~m})^{d}\left(\mathrm{~s}^{-1}\right)^{e}, \\
& {\left[\tau_{d}^{H}\right]^{1}=\left[\left.\overline{w^{\prime} u^{\prime}}\right|_{H}\right]^{a}[H]^{b}[L]^{c}[W]^{d}\left[\frac{\Delta U_{b}}{\Delta z}\right]^{e} .}
\end{aligned}
$$

The number of possible combinations of the variables whose time scale $\tau_{d}^{H}$ is given by the number of independent variables (5) minus the number of dimensions (2). In particular,

$$
\begin{aligned}
\text { [m] } 0 & =2 a+b+c+d, \\
{[\mathrm{~s}] } & 1=-2 a-e,
\end{aligned}
$$

which gives the following result:

$$
\begin{aligned}
& e=-2 a-1, \\
& c=-2 a-d-b .
\end{aligned}
$$

Since $a, b$, and $d$ are arbitrary coefficients, $a$ and $d$ are set equal to -1 while $b=3$. Therefore,

$$
a=-1, d=-1 \text { and } b=3 \rightarrow c=0 \text { and } e=1 .
$$

Substituting the coefficients in Eq. $13 \mathrm{~b}$ gives

$$
\left(\tau_{d}^{H}\right)^{1}=\left(\left.\overline{w^{\prime} u^{\prime}}\right|_{H}\right)^{-1} W^{-1} L^{0} H^{3}\left(\frac{\Delta U_{b}}{\Delta z}\right)^{1},
$$

and finally

$$
\tau_{d}^{H}=\frac{H^{3} \Delta U_{b}}{\left.\overline{w^{\prime} u^{\prime}}\right|_{H} W \Delta z} .
$$

\section{Appendix 2: Technical Specifications for the Instrumentation}

The following tables contain the main technical specifications for the instrumentation adopted in the experimental field campaign. Throughout the tables, r.m.s. is used for root mean square. Instrumentation deployed in Marconi Street is reported in Table 4.

The specifications of the instrumentation deployed in Silvani Street and Asinelli Tower are reported in Table 5. 
Table 4 Technical specifications of the instrumentation deployed in Marconi Street

Sonic-anemometer technical specifications

Windmaster 3D, Gill,

Lymington, Hampshire, UK

uSonic-3, Metek,

Elmshorn, Germany

Wind speed

\begin{tabular}{|c|c|c|}
\hline Range & $0-50 \mathrm{~m} \mathrm{~s}^{-1}$ & $0-60 \mathrm{~m} \mathrm{~s}^{-1}$ \\
\hline Accuracy & $\leq 1.0 \%$ r.m.s. at $12 \mathrm{~m} \mathrm{~s}^{-1}$ & $0.1 \mathrm{~m} \mathrm{~s}^{-1}$ \\
\hline Resolution & $0.01 \mathrm{~m} \mathrm{~s}^{-1}$ & $0.01 \mathrm{~m} \mathrm{~s}^{-1}$ \\
\hline \multicolumn{3}{|l|}{ Wind direction } \\
\hline Range & $0-359^{\circ}$ & $0-359^{\circ}$ \\
\hline Accuracy & $0.5^{\circ}$ r.m.s. at $12 \mathrm{~m} \mathrm{~s}^{-1}$ & $2^{\circ}$ at $5 \mathrm{~m} \mathrm{~s}^{-1}$ \\
\hline Resolution & $0.1^{\circ}$ & $0.1^{\circ}$ \\
\hline \multicolumn{3}{|l|}{ Sonic temperature } \\
\hline Range & $-40^{\circ} \mathrm{C}$ to $+70{ }^{\circ} \mathrm{C}$ & $-40^{\circ} \mathrm{C}$ to $+70^{\circ} \mathrm{C}$ \\
\hline Accuracy & $\pm 2{ }^{\circ} \mathrm{C}$ within $-20{ }^{\circ} \mathrm{C}$ to $+30{ }^{\circ} \mathrm{C}$ & $2{ }^{\circ} \mathrm{C}$ at $5 \mathrm{~m} \mathrm{~s}^{-1}$ \\
\hline Resolution & $0.01{ }^{\circ} \mathrm{C}$ & $0.01{ }^{\circ} \mathrm{C}$ \\
\hline \multicolumn{3}{|l|}{ Operating ranges } \\
\hline Relative humidity & $\leq 5 \%$ to $100 \%$ & $5 \%$ to $100 \%$ \\
\hline Temperature & $-40^{\circ} \mathrm{C}$ to $+70^{\circ} \mathrm{C}$ & $-40^{\circ} \mathrm{C}$ to $+60^{\circ} \mathrm{C}$ \\
\hline Precipitation & $300 \mathrm{~mm} \mathrm{hr}^{-1}$ & - \\
\hline
\end{tabular}

Thermohygrometer technical specifications

Thermometer HCS2S3,

Hygrometer HCS2S3,

Campbell Scientific, Logan,

Campbell Scientific, Logan,

Utah, USA

Utah, USA

\begin{tabular}{lll}
\hline Range & $-40{ }^{\circ} \mathrm{C}$ to $+60{ }^{\circ} \mathrm{C}$ & 0 to $100 \%$ \\
Accuracy & $\pm 0.1{ }^{\circ} \mathrm{C}$ at $23{ }^{\circ} \mathrm{C}$ & $\pm 0.8^{\%}$ at $23{ }^{\circ} \mathrm{C}$ \\
Long-term stability & $\leq 0.1^{\circ} \mathrm{C}$ year ${ }^{-1}$ & $\leq 1 \%$ year $^{-1}$ \\
Temperature ranges & & $-40{ }^{\circ} \mathrm{C}$ to $+100{ }^{\circ} \mathrm{C}$ \\
Operating & $-40{ }^{\circ} \mathrm{C}$ to $+100{ }^{\circ} \mathrm{C}$ & $-50{ }^{\circ} \mathrm{C}$ to $+100{ }^{\circ} \mathrm{C}$ \\
Storage & $-50{ }^{\circ} \mathrm{C}$ to $+100{ }^{\circ} \mathrm{C}$ & \\
\hline
\end{tabular}

Gas analyzer technical specifications

T300, Teledyne API, San Diego, California, USA

\begin{tabular}{ll}
\hline Range & $0-1000 \mathrm{ppm}$ full scale \\
Accuracy & $0.5 \%$ if reading above $5 \mathrm{ppm}$ \\
Operating range & $+5^{\circ} \mathrm{C}$ to $+40^{\circ} \mathrm{C}$ \\
Temperature & \\
\hline
\end{tabular}


Table 5 Technical specifications of the instrumentation deployed in Silvani Street and Asinelli Tower

\begin{tabular}{|c|c|c|}
\hline & $\begin{array}{l}\text { WMS301 and WMS302, Väisälä, } \\
\text { Helsinki, Finland }\end{array}$ & $\begin{array}{l}\text { Vv20 and Dv20, CAE, } \\
\text { Bologna, Italy }\end{array}$ \\
\hline \multicolumn{3}{|l|}{ Wind speed } \\
\hline Range & $0.5-60 \mathrm{~m} \mathrm{~s}^{-1}$ & $0-60 \mathrm{~m} \mathrm{~s}^{-1}$ \\
\hline Sensibility & $<0.02 \mathrm{~m} \mathrm{~s}^{-1}$ & $<0.02 \mathrm{~m} \mathrm{~s}^{-1}$ \\
\hline Accuracy & $\begin{array}{l} \pm 0.3 \mathrm{~m} \mathrm{~s}^{-1} \text { if } \leq 10 \mathrm{~m} \mathrm{~s}^{-1} \\
<2 \% \text { if }>10 \mathrm{~m} \mathrm{~s}^{-1}\end{array}$ & $\begin{array}{l} \pm 0.07 \mathrm{~m} \mathrm{~s}^{-1} \\
\text { or }<1 \%\end{array}$ \\
\hline Resolution & - & $0.06 \mathrm{~m} \mathrm{~s}^{-1}$ \\
\hline Starting threshold & $0.4 \mathrm{~m} \mathrm{~s}^{-1}$ & $0.5 \mathrm{~m} \mathrm{~s}^{-1}$ \\
\hline \multicolumn{3}{|l|}{ Wind direction } \\
\hline Range & $0-355^{\circ}$ & $0-360^{\circ}$ \\
\hline Accuracy & $\pm 3^{\circ}$ & $\pm 2.8^{\circ}$ \\
\hline Resolution & - & $0.35^{\circ}$ \\
\hline $\begin{array}{l}\text { Starting threshold } \\
\text { Operating ranges }\end{array}$ & $<1.0 \mathrm{~m} \mathrm{~s}^{-1}$ & - \\
\hline \multirow[t]{2}{*}{ Temperature } & $-40{ }^{\circ} \mathrm{C}$ to $+55^{\circ} \mathrm{C}$ & $-30{ }^{\circ} \mathrm{C}$ to $+60{ }^{\circ} \mathrm{C}$ \\
\hline & $\begin{array}{l}\text { HMP230, Väisälä, } \\
\text { Helsinki, Finland }\end{array}$ & $\begin{array}{l}\text { THS, CAE, } \\
\text { Bologna, Italy }\end{array}$ \\
\hline \multicolumn{3}{|l|}{ Thermometer } \\
\hline Range & $-40^{\circ} \mathrm{C}$ to $+60^{\circ} \mathrm{C}$ & -50 to $+100^{\circ} \mathrm{C}$ \\
\hline Accuracy & $\pm 0.1^{\circ} \mathrm{C}$ at $20^{\circ} \mathrm{C}$ & $\pm 0.2{ }^{\circ} \mathrm{C}$ at $23{ }^{\circ} \mathrm{C}$ \\
\hline \multicolumn{3}{|l|}{ Hygrometer } \\
\hline Range & $0-100 \%$ & $0-100 \%$ \\
\hline Accuracy & $\begin{array}{l} \pm 1 \% \text { if } 0-90 \% \\
\pm 2 \% \text { if } 90-100 \%\end{array}$ & $\pm 1.5 \%$ \\
\hline \multicolumn{3}{|l|}{ Temperature ranges } \\
\hline Operating & $-40{ }^{\circ} \mathrm{C}$ to $+60{ }^{\circ} \mathrm{C}$ & $-20{ }^{\circ} \mathrm{C}$ to $+50{ }^{\circ} \mathrm{C}$ \\
\hline Storage & $-40^{\circ} \mathrm{C}$ to $+70^{\circ} \mathrm{C}$ & - \\
\hline
\end{tabular}

\section{References}

Bady M, Kato S, Huang H (2008) Towards the application of indoor ventilation efficiency indices to evaluate the air quality of urban areas. Build Environ 43(12):1991-2004

Barlow JF, Belcher SE (2002) A wind tunnel model for quantifying fluxes in the urban boundary layer. Bound-Layer Meteorol 104:131-150

Barlow JF, Harman IN, Belcher SE (2004) Scalar fluxes from urban street canyons. Part I: laboratory simulation. Bound-Layer Meteorol 113:369-385

Bentham T, Britter R (2003) Spatially averaged flow within obstacle arrays. Atmos Environ 37(15):2037-2043

Britter RE, Hanna SR (2003) Flow and dispersion in urban areas. Annu Rev Fluid Mech 35(1):469-496

Buccolieri R, Sandberg M, Di Sabatino S (2010) City breathability and its link to pollutant concentration distribution within urban-like geometries. Atmos Environ 44(15):1894-1903

Buccolieri R, Salizzoni P, Soulhac L, Garbero V, Di Sabatino S (2015) The breathability of compact cities. Urban Clim 13:73-93

Chen L, Hang J, Sandberg M, Claesson L, Di Sabatino S, Wigo H (2017) The impacts of building height variations and building packing densities on flow adjustment and city breathability in idealized urban models. Build Environ 118:344-361 
Cheng WC, Liu CH, Leung DYC (2009a) On the comparison of the ventilation performance of street canyons of different aspect ratios and Richardson number. Build Simul 2(1):53-61

Cheng WC, Liu CH, Leung DYC (2009b) On the correlation of air and pollutant exchange for street canyons in combined wind-buoyancy-driven flow. Atmos Environ 43(24):3682-3690

Dallman A, Di Sabatino S, Fernando HJ (2013) Flow and turbulence in an industrial/suburban roughness canopy. Environ Fluid Mech 13(3):279-307

Dallman A, Magnusson S, Britter R, Norford L, Entekhabi D, Fernando HJS (2014) Conditions for thermal circulation in urban street canyons. Build Environ 80:184-191

Di Bernardino A, Monti P, Leuzzi G, Querzoli G (2018) Pollutant fluxes in two-dimensional street canyons. Urban Clim 24:80-93

Di Sabatino S, Buccolieri R, Pulvirenti B, Britter RE (2007) Simulations of pollutant dispersion within idealised urban-type geometries with CFD and integral models. Atmos Environ 41(37):8316-8329

Di Sabatino S, Leo LS, Cataldo R, Britter RE (2010) Construction of digital elevation models for a Southern European city and a comparative morphological Analysis with Respect to Northern European and North American Cities. J Appl Meteorol Clim 49:1377-1396

Durst F (2008) Similarity theory. In: Durst F (ed) Fluid mechanics. Springer, Berlin

Eliasson I, Offerle B, Grimmond CSB, Lindqvist S (2006) Wind fields and turbulence statistics in an urban street canyon. Atmos Environ 40:1-16

European Environment Agency (2016) EMEP/EEA air pollutant emissions inventory guidebook 2016: technical guidance to prepare national emission inventories. EEA Report No 21/2016

Finardi S, Silibello C, Allura D, Radice AP (2014) Analysis of pollutants exchange between the Po Valley and the surrounding European region. Urban Clim 10:682-702

Hang J, Sandberg M, Li Y (2009) Age of air and air exchange efficiency in idealized city models. Build Environ 44(8):1714-1723

Hang J, Li Y, Buccolieri R, Sandberg M, Di Sabatino S (2012) On the contribution of mean flow and turbulence to city breathability: the case of long streets with tall buildings. Sci Tot Environ 416:362-373

Hang J, Luo Z, Sandberg M, Gong J (2013) Natural ventilation assessment in typical open and semi-open urban environments under various wind directions. Build Environ 70:318-333

Harman IN, Barlow JF, Belcher SE (2004) Scalar Fluxes from urban street Canyons Part II: model. BoundLayer Meteorol 113(3):387-410

Højstrup J (1993) Statistical data screening procedure. Meas Sci Technol 4(2):153-157

Kanda M, Moriwaki R (2006) Spatial variability of both turbulent fluxes and temperature profiles in an urban roughness layer. Bound-Layer Meteorol 121(2):339-350

Kastner-Klein P, Rotach MW (2004) Mean flow and turbulence characterisitcs in a urban roughness sublayer. Bound-Layer Meteorol 111:55-84

Kastner-Klein P, Berkowicz R, Britter R (2004) The influence of street architecture on flow and dispersion in street canyons. Meteorol Atmos Phys 87:121-131

Kato S, Huang H (2009) Ventilation efficiency of void space surrounded by buildings with wind blowing over built-up urban area. J Wind Eng Ind Aerodyn 97(7-8):358-367

Kim JJ, Baik JJ (2003) Effects of inflow turbulence intensity on flow and pollutant dispersion in an urban street canyon. J Wind Eng Ind Aerodyn 91(3):309-329

Klein PM, Galvez JM (2015) Flow and turbulence characteristics in a suburban street canyon. Environ Fluid Mech 15:419-438

Kotz S, Nadarajah S (2000) Extreme value distributions: theory and applications. Imperial College Press, London

Kubilay A, Ma Neophytou, Matsentides S, Loizou M, Carmeliet J (2017) The pollutant removal capacity of an urban street Canyon and its link to the breathability and exchange Velocity. Procedia Eng 180:443-451

Leo LS, Buccolieri R, Di Sabatino S (2018) Scale-adaptive morphometric analysis for urban air quality and ventilation applications. Build Res Inf 46(8):931-951

Li XX, Britter RE, Norford LK, Koh TY, Entekhabi D (2012) Flow and pollutant transport in urban street Canyons of different aspect ratios with ground heating: large-eddy simulation. Bound-Layer Meteorol 142(2):289-304

Li XX, Britter RE, Norford LK (2015) Transport processes in and above two-dimensional urban street canyons under different stratification conditions: results from numerical simulation. Environ Fluid Mech 15(2):399-417

Li XX, Britter R, Norford LK (2016) Effect of stable stratification on dispersion within urban street canyons: a large-eddy simulation. Atmos Environ 144:47-59

Liu CH, Wong CC (2014) On the pollutant removal, dispersion, and entrainment over two-dimensional idealized street canyons. Atmos Res 135:128-142 
Liu CH, Leung DYC, Barth MC (2005) On the prediction of air and pollutant exchange rates in street canyons of different aspect ratios using large-eddy simulation. Atmos Environ 39(9):1567-1574

Lo KW, Ngan K (2017) Characterizing ventilation and exposure in street canyons using Lagrangian particles. J Appl Meteorol Clim 56(5):1177-1194

Louka P, Belcher S, Harrison R (1998) Modified street canyon flow. J Wind Eng Ind Aerodyn 74:485-493

Louka P, Belcher SE, Harrison RG (2000) Coupling between air flow in streets and the well-developed boundary layer aloft. Atmos Environ 34(16):2613-2621

Mazzola M, Lanconelli C, Lupi A, Busetto M, Vitale V, Tomasi C (2010) Columnar aerosol optical properties in the Po Valley, Italy, from MFRSR data. J Geophys Res Atmos 115:1-17

McMillen R (1988) An eddy correlation technique with extended applicability to non-simple terrain. BoundLayer Meteorol 43(3):231-245

Murena F, Favale G (2007) Continuous monitoring of carbon monoxide in a deep street canyon. Atmos Environ 41:2620-2629

Nazarian N, Martilli A, Kleissl J (2017) Impacts of Realistic urban heating, Part I: Spatial variability of mean flow, turbulent exchange and pollutant dispersion. Bound-Layer Meteorol 166:367-393

Nazarian N, Martilli A, Norford L, Kleissl J (2018) Impacts of realistic urban heating. Part II: air quality and city breathability. Bound-Layer Meteorol 168:321-341

Nelson MA, Pardyjak ER, Klein P (2011) Momentum and turbulent kinetic energy budgets within the park avenue street canyon during the joint urban 2003 field campaign. Bound-Layer Meteorol 140:143-162

Oke T (1987) Boundary layer climates, 2nd edn. Routledge, Methuen

Panagiotou I, Neophytou MKA, Hamlyn D, Britter RE (2013) City breathability as quantified by the exchange velocity and its spatial variation in real inhomogeneous urban geometries: An example from central London urban area. Sci Tot Environ 442:466-477

Ratti C, Di Sabatino S, Britter R, Brown M, Caton F, Burian S (2002) Analysis of 3-D urban databases with respect to pollutant dispersion for a number of European and American cities. Water Air Soil Pollut 2:459-469

Rotach MW, Vogt R, Bernhofer C, Batchvarova E, Christen A, Clappier A, Feddersen B, Gryning SE, Martucci G, Mayer H, Mitev V, Oke TR, Parlow E, Richner H, Roth M, Roulet YA, Ruffieux D, Salmond JA, Schatzmann M, Voogt JA (2005) BUBBLE-an urban boundary layer meteorology project. Theor Appl Climatol 81:231-261

Salizzoni P, Soulhac L, Mejean P (2009) Street canyon ventilation and atmospheric turbulence. Atmos Environ 43(32):5056-5067

Salizzoni P, Marro M, Soulhac L, Grosjean N, Perkins RJ (2011) Turbulent transfer between street canyons and the overlying atmospheric boundary layer. Bound-Layer Meteorol 141(3):393-414

Schmid HP, Grimmond CB, Cropley F, Offerle B, Su HB (2000) Measurements of CO2 and energy fluxes over a mixed hardwood forest in the mid-western United States. Agric For Meteorol 103(4):357-374

Solazzo E, Britter RE (2007) Transfer processes in a simulated urban street canyon. Bound-Layer Meteorol $124: 43-60$

Soulhac L, Salizzoni P (2010) Dispersion in a street canyon for a wind direction parallel to the street axis. J Wind Eng Ind Aerodyn 98(12):903-910

Soulhac L, Perkins RJ, Salizzoni P (2008) Flow in a street canyon for any external wind direction. Bound-Layer Meteorol 126:365-388

Vickers D, Mahrt L (1997) Quality control and flux sampling problems for tower and aircraft data. J Atmos Ocean Technol 14(3):512-526

Winkler SL, Anderson JE, Garza L, Ruona WC, Vogt R, Wallington TJ (2018) Vehicle criteria pollutant (PM, NOx, CO, HCs) emissions: how low should we go? Clim Atmos Sci 1(26):1-5

Zajic D, Fernando HJ, Calhoun R, Princevac M, Brown MJ, Pardyjak ER (2011) Flow and turbulence in an urban canyon. J Appl Meteorol Clim 50(1):203-223

Publisher's Note Springer Nature remains neutral with regard to jurisdictional claims in published maps and institutional affiliations. 